2022 TheoLogica

An International Journal for Philosophy of Religion and Philosophical Theology

S. I. RESTORING HUMAN NATURE

DOI: https://doi.org/10.14428/thl.v6i1.61263

\title{
A Theological Engagement with the Science of Science Skepticism
}

\author{
JOSH REEVES \\ Samford University \\ jareeves@samford.edu
}

\begin{abstract}
When Christians reject the claims of scientific experts, are they being irrational? Much of recent discussion in scholarly and popular media have discussed science denialism by conservative Christians, linking a low view of scientific expertise to the United States' current political turmoil. ${ }^{1}$ This paper will focus on scientific explanations of science skepticism, asking whether there is anything unique to religious communities that make them vulnerable to misinformation.
\end{abstract}

Keywords: science skepticism, mistrust of science, theology, science

This paper will focus on scientific explanations of science skepticism, asking whether there is anything unique to religious communities that make them vulnerable to misinformation. When surveying the social science literature, at least three explanations (misleading cognitive biases are in operation, humans care more for group identity than truth, or human reasoners want truth but rely upon intellectual shortcuts) emerge for describing why some communities have difficulty accepting scientific information. While these positions are not mutually exclusive, I argue in what follows the last one is the most pervasive and has the most explanatory power. If this is the case, then religious skepticism is fueled more Christian intellectual culture than cognitive mechanisms.

\section{Explanation 1: Individual Cognitive Biases}

Many recent explanations for science skepticism have focused on cognitive biases that make it difficult for the public to make reasoned decisions about scientific claims. One of the most influential ways to discuss biases in human cognition is to distinguish between two different modes of cognitive processing called System 1

\footnotetext{
${ }^{1}$ Stewart (2020).
} 
and System 2. ${ }^{2}$ System-1 thinking is fast and automatic and includes emotion and intuition. System-2 employs the conscious processes of the mind, which require working memory and are slower and more deliberative than System 1 thinking. Advocates of this theory say that we normally rely upon System 1 because it requires less effort than System 2 and is often correct but that we can override our intuitive responses if we come to a different conclusion through deliberation. In sum, evolution has equipped our brain with systematic biases, with shortcuts that allow us to make quick decisions that promote survival over finding the truth.

Examples of System-1 biases include the affect heuristic, wherein judgments are guided directly by feelings of liking and disliking rather than by conscious reasoning. ${ }^{3}$ The immediacy bias says that, when one is feeling hunger, it is difficult to project the level of hunger for the following day. ${ }^{4}$ Numerous other biases (e.g., positive illusions, cognitive dissonance, the fundamental attribution error, prospect theory, hindsight bias, and the gamblers fallacy) have been suggested, which together paint a bleak picture of human rationality. ${ }^{5}$ Two cognitive psychologists summarize the data as follows: "On their own, individuals are not well equipped to separate fact from fiction, and they never will be. Ignorance is our natural state; it is a product of the way the mind works." 6 To add insult to injury, studies also show that the more incompetent or ignorant one is, the less one can recognize it (the Dunning-Kruger effect). ${ }^{7}$

Once one has uncovered the psychological basis of human biases, it is easy to link those biases to science denial. Because of the human tendency to rely upon intuitive heuristics when judging information, extra effort is required to learn or retain scientific concepts that cut against the grain of System-1 processes. With respect to climate change, for example, two researchers argue as follows: "People's attitudes to the environment can better be explained and predicted-over and above any actual facts about environmental change - by taking into account the psychological

2 Kahneman (2011); Evans and Stanovich (2013, 223-41).

${ }^{3}$ Kahneman $(2011,12)$.

${ }^{4}$ Gilbert, Gill, and Wilson (2002, 430-44).

${ }^{5}$ Other proposed biases include confirmation bias. Nickerson (1998); myside bias (Stanovich, West, and Toplak (2013), bias blind spots Pronin, Lin, and Ross (2002), and overreliance on a number of heuristics and biases (Tversky, Amos, and Kahneman 1974).

${ }^{6}$ Fernbach and Sloman (2018).

${ }^{7}$ Kruger and Dunning $(1999,1121)$. They say: "When people are incompetent in the strategies they adopt to achieve success and satisfaction, they suffer a dual burden: Not only do they reach erroneous conclusions and make unfortunate choices, but their incompetence robs them of the ability to realize it. Instead, like Mr. Wheeler, they are left with the erroneous impression they are doing just fine." 
biases inherent to the human brain." 8 Though humans have the ability for abstract thought and can conceive future alternatives, our attention is normally drawn back to our surrounding environment. The effects of global warming are thought to be too far in the future and too nebulous for most people to connect them to events in daily life. In a comparable way, students have a hard time learning evolutionary principles because they "enter their biology classes with a host of misconceptions that are never explicitly addressed or refuted." ${ }^{\prime 9}$ Essentialist biases give people the idea that species are stable and immutable, and teleological biases lead people to seek purposeful explanations..$^{10}$ Because objects in the world are intuitively imbued with function and purpose, it is much easier to grasp supernatural concepts than biological ones. ${ }^{11}$ Giving information without first combating the specific biases that cause students to discount it is a waste of effort, for our intuitions powerfully shape our reasoning when we are unconscious of them. ${ }^{12}$ Education should help students become aware of their own misleading intuitions and, if possible, train new responses. ${ }^{13}$

Explanation 1 is unlikely to be the best explanation for science skepticism for many reasons. Cognitive biases cannot explain the variance of science skepticism among diverse groups. Why are Germans less skeptical about climate change than Americans, given that they share the same cognitive mechanisms? A second reason that Explanation 1 is insufficient is that there seems to be a bias for psychologists and other social scientists to find bias when there is none. ${ }^{14}$ The issue is not that humans are irrational, but whether irrationality is systematic and often undetected, because it goes against everyday experience and intuition. Biases are supposed to be like visual illusions; universally hardwired into the brain and thus hard to change by education. ${ }^{15}$ But research shows, as I will argue below, that people can update

\footnotetext{
${ }^{8}$ Johnson (2009).

${ }_{9}^{9}$ Bishop and Anderson (1990, 415-27). "Evolution is an exceedingly difficult theory to understand and is counterintuitive due to multiple cognitive biases. Essentialist biases lead people to believe that species are stable and immutable. Teleological biases lead us to believe that all species and their component parts exist for a reason." Kumandaş, Ateskan, and Lane (2019, 350-64).

10 "A broad teleological tendency therefore appears to be a robust, resilient, and developmentally enduring feature of the human mind that arises early in life and gets masked rather than replaced, even in those whose scientific expertise and explicit metaphysical commitments seem most likely to counteract it." (Kelemen, Rottman, and Seston 2013, 8).

${ }^{11}$ Gervais $(2015,312-21)$.

${ }^{12}$ Pennycook, Fugelsang, and Koehler (2015, 425-32).

${ }^{13}$ Cook, Ecker, and Lewandowsky (2015, 1-17).

${ }^{14}$ The critiques in this section follow Gerd Gigerenzer (2018, 303-36).

${ }^{15}$ Gigerenzer (2018, 304).
} 
their beliefs through education. And many of these biases - Wikipedia currently lists over two hundred-either are common sense or counterintuitive experimental findings that often are later overturned. For example, it was once frequently argued (and could be found on the NCAA website) that there was such a thing as the hot hand fallacy, the idea that a player can get "hot" when in fact past performance has no influence on future outcomes. ${ }^{16}$ It turns out through a reanalysis of the data that someone with a hot hand in basketball has a 11 percent better chance of making the shot-roughly the difference between an average and the best NBA three-point shooter. Basketball players and coaches would have been better served by trusting their own experience to the statistical analysis of social scientists. Social scientists need to be more vigilant to root out the biases in their own research that they find so easily in others.

\section{Explanation 2: Rationality as a Social Bonding Strategy}

A second general approach argues that we should look to social explanations to understand the prevalence of science skepticism. While the cognitive biases considered in the previous section play a role in belief formation, they cannot explain the variance of science skepticism among diverse groups. Why are Germans less skeptical about climate change than Americans given that they share the same cognitive mechanisms? The answer for many social scientists is that we should consider how humans act in groups.

The primary role of human reason, as some social psychologists have argued in recent years, is not to ascertain the truth but to maintain bonds with others in one's social network. Humans are social creatures who are easily turned against others who are perceived to be outsiders - even when placed in randomly and arbitrarily formed groups. ${ }^{17}$ Reason functions as a lawyer who will find the best arguments to an existing conclusion rather than forming accurate beliefs relative to the best evidence..$^{18}$ As one political scientist summarizes: "In matters of public opinion, citizens seem to ask themselves not 'What's in it for me?' but 'What's in it for my group?'"19 It is human reasoning ability that allows people to be so unreasonable. If rejecting climate change becomes part of the core beliefs of being a Republican, for example, then the burden of proof for changing one's mind for those who identify as Republican becomes exponentially higher. Such explanations are cultural-

\footnotetext{
${ }^{16}$ Gigerenzer $(2018,316)$.

${ }^{17}$ Johnson and Levin (2009, 1598); Haidt (2013, 219ff).

${ }_{18}$ Mercier and Sperber $(2011,80)$; Mercier $(2016,689-700)$.

${ }^{19}$ Haidt (2013, 100); Kinder (1998 808).
} 
unique to American political history, for example-as they do not depend on cognitive mechanisms alone.

What makes explanation 2 different from the intuition-bias explanation described above is that it places more blame on our analytic-reasoning (System-2) processes than on the intuitions of System 1. We use higher-order reasoning to find arguments that can convince others and maintain our status in a group. Analytic reasoning allows us to find information that favors our own cultural, religious, and political commitments. ${ }^{20}$ In short, it is human reasoning ability that allows people to be so unreasonable. This account is supported by evidence that the more intelligent a person is, the greater the chance for political polarization around contentious issues, such as climate change or gun control. ${ }^{21}$ Psychologists have shown that individuals who score the highest on a number of science-comprehension tests are more polarized than those who rely upon their intuitive reasoning. ${ }^{22}$ Climate-change and evolution deniers often have much more extensive knowledge of scientific processes than those who do not. Cognitive sophistication can lead to inferior viewpoints being more persuasively defended. ${ }^{23}$

Appealing to the use of reason to resist rationally superior explanations also helps to explain a puzzling phenomenon in the field of science communication: Scholars have often assumed that public skepticism of science is driven by a lack of information. This assumption has encouraged the belief that the public would be persuaded if science popularizers could only inform it about the facts or the state of scientific consensus. The reality, however, is that publicity campaigns can have the opposite effect, thus demonstrating a "backfire effect" that increases skepticism towards a theory. ${ }^{24}$ For example, despite efforts by $\mathrm{Al}$ Gore and others to convince the American public about the realities of global warming, belief that global warming is a problem actually decreased in the U.S. from $79 \%$ to $59 \%$ over the period 2006-2010. The backfire effect has been found in studies on a variety of issues, from vaccines to the supposed introduction of "death panels" by the Affordable Care Act. ${ }^{25}$ Science-education campaigns backfire because it is hard to abandon core

\footnotetext{
${ }^{20}$ Kahan (2012); Kahan et al. (2017, 179-99).

${ }^{21}$ Kahan et al. (2012, 732-35); Sarathchandra et al. (2018, 1-7).)

22 Kahan et al., (2017, 54-86).

${ }^{23}$ Bolsen, Druckman, and Cook (2015); Hamilton, Cutler, and Schaefer (2012); Drummond and Fischhoff $(2017,9587-92)$.

${ }^{24}$ Nyhan and Reifler $(2010,312)$.

${ }^{25}$ Nyhan et al. (2014, 2013-2365); Berinsky (2017, 241-62).
} 
beliefs that are critical to one's identity, as to do so would also undermine one's membership in the group. ${ }^{26}$

If Explanation 2 is correct, then one solution to science skepticism would be to build trust by using science educators who identify closely with a targeted group, as new information will be accepted only by those who are on one's own "team." ${ }^{27}$ Explanation 2 also suggests that effective science communication must convey the message that a particular scientist shares the values of the community to which he or she is speaking; otherwise, attempts at education will have little effect and may even have the opposite effect. ${ }^{28}$ Skepticism could also be lessened by creating opportunities for personal interactions between laypeople and scientists, as trust is best created in face-to-face interactions. ${ }^{29}$ Finally, people often identify with multiple groups: religiously, culturally, ethically, and economically. When one is attempting to target a community for scientific education, one needs to consider the multiple ways that one's presentation can be tailored to that specific group.

Critics of Explanation 2 argue that disinterest in truth in favor of group identity has not been seen in numerous recent studies. People update their beliefs when presented with evidence about the scientific evidence of climate change, regardless of prior motivation or political motivation. ${ }^{30}$ Other studies show that training in detecting fake news decreases belief regardless of political identity and that the backfire effect is the exception rather than usual occurrence..$^{31}$ In other words, more reasoning leads to more accurate beliefs. As two political scientists argue, "Evidence we've gathered over the previous four years-involving more than 10,000 participants and spanning from the 2016 election to well into the Trump presidency -illustrates that the most pessimistic accounts of the decline of facts are, well, not entirely factual." 32 I think overall that recent evidence shows that while individuals trust information from their social groups, most persons are still interested in truth. What leads certain groups to inaccurate conclusions is the lack of exposure to quality information rather than the explicit rejection of what they

\footnotetext{
${ }^{26}$ Pentland (2016).

${ }^{27}$ Goldberg et al. (2019).

${ }^{28}$ Holt, Ogden, and Durham (2018, 11); Irzik and Kurtulmus (2019, 1145-66).

${ }^{29}$ Funk, Johnson, and Hefferon (2019): “Half or more of Americans have positive views about each of six professional groups asked about in the survey. The public is warmest toward medical doctors: About three-quarters. Majorities also have positive opinions of medical researchers (68\%), dietitians (60\%), environmental health specialists (60\%) and environmental researchers (57\%). About half (51\%) have positive overall views of nutrition researchers."

${ }^{30}$ Linden, Maibach, and Leiserowitz $(2019,1-8)$.

${ }^{31}$ Roozenbeek and Linden (2019, 1-10); Wood and Porter (2019, 135-63).

32 Porter and Wood (2020).
} 
know is likely to be true, a finding that has been shown in religious believers. ${ }^{33} \mathrm{In}$ other words, more reasoning leads to more accurate beliefs.

\section{Explanation 3: It Is Rational to Trust}

The third explanation assumes that, despite cognitive shortcomings and the tempting reversion to group identity, the intent of human reasoning is truth. ${ }^{34}$ This is the classical way of construing human reason, as it says that deliberation results in a greater ability to discern what is correct. ${ }^{35}$ The real problem with human reason is not that our inbuilt intuitions mislead us but rather that most people do not take the time to improve their intuitions (System 1) through explicit reasoning (System 2). When bad information is accepted, it is probably because the individual failed to cognitively reflect on what was being claimed or on the source of that claim.

The ability to make discerning choices about which beliefs to accept from others is what many philosophers and psychologists call "epistemic vigilance." 36 All humans are inclined to weigh information, otherwise we could not thrive, or even survive, for we would then lack the skills we need to navigate modern life. ${ }^{37} \mathrm{Without}$ vigilance, we would fall for every get-rich-quick scheme or other plan to take our money and attention. Because of the importance of discernment with respect to information, even children are not automatically trusting when it comes to accepting beliefs from others. ${ }^{38}$ Children have been shown in developmental studies to resist testimony that conflicts with their own prior observations. They can also grasp the difference between stories that aim to represent reality and those that do not, can monitor informants to assess their reliability, and will correct a parent/teacher who gives inaccurate information. Rather than believing anything they are told, children from three years of age have limits on what they are willing to believe and are developing the general human tendency to weigh information from others.

The concept of epistemic vigilance helps to explain why Christians support science skepticism. One problem with respect to science is that the public cannot verify the outcome of experiments or the evidence that supports a theory. When

\footnotetext{
${ }^{33}$ Gervais $(2015,319)$.

${ }_{34}$ Evans and Stanovich (2013); Pennycook and Rand, (2019); Shtulman and McCallum (2014); Stanovich (2011); Swami, Voracek, Stieger, Tran, and Furnham(2014). Gervais (2015).

35 Pennycook and Rand $(2019,39-50)$.

${ }^{36}$ Dan Sperber et al. (2010, 359-93). As they say: "Epistemic vigilance, unlike distrust, is not the opposite of trust; it is the opposite of blind trust."

${ }^{37}$ Collins and Evans $(2007,16)$.

${ }^{38}$ Sperber et al. (2010, 371ff).
} 
considering an expert's claim, one often relies upon secondary considerations to make a judgement about its validity - what the sociologist Harry Collins calls our use of "social knowledge." ${ }^{39}$ When a quantum physicist tells us about the behavior of electrons, most of us cannot assess the scientific claim - for we lack the technical knowledge and skills to do so. What we can assess is his or her credentials, place of employment, schooling, demeanor, appearance, speaking ability, social skills, respect of peers, experience, and record of accomplishment; we can also judge how well the statements fit with what we already believe and so on. If the speaker seems credible according to these secondary criteria, we are much more warranted in trusting him or her than we would be otherwise. Unfortunately, it is far from ideal to evaluate experts through secondary criteria. The inferior nature of social knowledge in comparison to personal knowledge has long been recognized in Western philosophy. In his classic dialogue Gorgias, Plato imagines a scenario in which an audience must distinguish a doctor from an imposter with excellent rhetoric. The character of Socrates agrees that the rhetorician will convince the crowd each time. ${ }^{40} \mathrm{~A}$ similar dilemma is faced by the public when scientists make claims about the natural world: Should one trust the scientific information despite lacking the ability to verify what is being claimed? Or should one remain skeptical towards statements that one cannot personally verify?

True epistemic vigilance is difficult, as it takes effort to continually watch our informants and evaluate their performance and trustworthiness. ${ }^{41}$ Many people make these decisions implicitly, using System 1, relying upon inarticulate feelings about who to trust, which is influenced by one's social community. "Tribal rationality", from this perspective, is not an illogical tendency to believe whatever your superiors tell you but is rather a useful shortcut that relieves one of the cognitive burdens of having to assess someone's trustworthiness. If one wants to know what to believe about a new policy proposal, one can simply look to see what others in one's group think about it, since they share one's values. Even in a modern society with easy access to information, most citizens rarely have the luxury to research issues in depth, as they must instead focus on the practical necessities of

\footnotetext{
${ }^{39}$ Collins and Evans $(2002,258)$.

40 "And I say that if a rhetorician and a physician were to go to any city, and had there to argue in the Ecclesia or any other assembly as to which of them should be elected state-physician, the physician would have no chance; but he who could speak would be chosen if he wished; and in a contest with a man of any other profession the rhetorician more than anyone would have the power of getting himself chosen, for he can speak more persuasively to the multitude of any of them, and on any subject. Such is the nature and power of the art of rhetoric!"

${ }^{41}$ Sperber et al. (2010, 360).
} 
working and caring for their families. ${ }^{42}$ When political debates occur between people, for example, what may on the surface appear to be simple disagreements about the facts of the matter are actually disagreements about perceived authorities: Where does this information come from, and is this source reliable and worthy of respect? ${ }^{43}$ Tribal rationality can give rise to groupthink, whereby positions are accepted on the basis of social pressure rather than of best evidence, but this does not negate all of the other occasions in life when relying upon one's group is a useful cognitive shortcut. ${ }^{44}$

Relying on others for information is not in itself irrational. The real problem is the number of uninformed or bad actors who are seeking to manipulate human trust for selfish gain. As one scholar who studies scientific communication says, "The problem, in short, is not a gullible, manipulated public; it is a polluted science communication environment." ${ }^{45}$ It is important to consider how difficult it is for laypeople acting on their own to discern what is reliable scientific information when so many individuals and institutions fill the information space with misleading or incorrect arguments. The difficulty has been documented by historians of science Naomi Oreskes and Eric Conway in Merchants of Doubt. They show that, to push misleading science to the public-thereby to create uncertainty about whether smoking causes cancer-cigarette companies need not provide convincing evidence for their position; they need only create the "appearance of doubt" by hiring freelance scientists who will support the company's message that the link between tobacco and cancer is unproven. If an intelligent member of the public who is actively seeking the truth encounters debates by scientists on opposite sides of an issue, is it is difficult to expect that person to determine which scientist is making the better use of evidence or best represents the judgment of the scientific community. The reason the tobacco strategy works is that laypeople, most of whom have no scientific training in a college or university, find it difficult to assess competing scientific claims. ${ }^{46}$ As long as the scientific evidence is perceived to be uncertain, there is no reason to act.

${ }^{42}$ Christiano (2017).

${ }^{43}$ Herritt $(2016,79)$.

${ }^{44}$ Ehret, Sparks, and Sherman (2017, 253-77); Gustafson et al. (2019, 940-44); Kahan (2016, 11): “It is perfectly rational for them consciously to seek out guidance from such individuals, then, or to form unconscious habits of mind that privilege them as sources of guidance on what science knows. This process is admittedly insular, but it clearly works in the main."

${ }^{45}$ Kahan (2017).

${ }^{46}$ Miller, Scott, and Okamoto (2006, 765-66). 
The problem of information-space pollution is that it can manipulate intellectual virtues that lead to truth, such as intellectual humility. When the public is confronted with two experts on climate change who disagree on the facts and the best interpretation of evidence, what is the right conclusion to draw? An emphasis on intellectual humility would suggest that, since scientists cannot agree, a layperson cannot be confident either. Intellectual humility is an important virtue, but it can be manipulated by those outside the scientific consensus to increase skepticism towards mainstream science.

In summary, recent research shows that communities are not, as some have argued, hermetically-sealed information bubbles in which people are resistant to any views that are not consistent with their own. ${ }^{47}$ While people do express a preference for information that is consistent with their own previous beliefs, they do not automatically reject information from other ideological sources. ${ }^{48}$ Rather than view the public as credulous consumers of misinformation, it is better to see much of the public as constrained consumers who reason by seeking out information and beliefs from cultural groups with which they identify. ${ }^{49}$ The difference is that the public will not believe just anything but can be misled by relying upon faulty information from trusted sources. In other words, reliance upon rational shortcuts, which are often effective in many domains of life, can be manipulated for economic or political gain.

If Explanation 3 is correct, then much of science skepticism is driven by an informational landscape that is too difficult for most people to navigate on their own. Even when we move people to think - to use their higher-level analytical thinking rather than rely upon intuitive processing-laypeople do not have enough background information to make decisions for themselves and lack sufficiently clear social knowledge to discern where reliable information is to be found. Given all the cognitive shortcomings in human nature, we still need to provide more opportunities for laypeople to reflect on science and teach them how to distinguish between quality knowledge and inferior knowledge. The problem with the Internet

47 Barberá et al. (2015, 1531-42); Dvir-Gvirsman, Tsfati, and Menchen-Trevino (2016). Gentzkow and Shapiro (2011, 1799-1839).

48 "Some surveys show that laypeople with more knowledge may be more skeptical towards science than those without a little training, since the illusion of comprehension gives one more selfconfidence in one's beliefs than is warranted." Lisa Scharrer et al. (2017, 1003-18).

${ }^{49}$ Kahan $(2017,9)$. 
and social media thus may not be fake news but rather that they exacerbate the human tendency to rely upon intuition when casually taking in information..$^{50}$

Applied to Christian communities, science skepticism does not originate from a casual dismissal of truth but rather from deeply held support for other truth claims, such as claims regarding the supernatural origin of the Bible and God's providential control over nature. While these beliefs are reinforced in social settings such as worship services, they also comprise narrative frameworks that Christians use to interpret the private experiences of their own lives. When Christians are told by influential members of the community that mainstream science conflicts with their own religious beliefs, and given that mainstream science is irrelevant to their own personal experience, Christians will reject the scientific data or accept the pseudoscience that is presented to them. Christians reason about evolution in the same way as nonreligious laypeople who accept evolution: Information is filtered through trusted sources. If Christians are to accept mainstream scientific theories, they will have to encounter factual information about science from people they trust, and it will need to at least generally cohere with core faith claims they believe.

\section{Conclusion}

This paper has outlined three ways of understanding scientific skepticism. Though Explanation 3 (that humans are limited but truth-seeking reasoners) has been found superior to Explanations 1 (cognitive biases impede scientific understanding) and 2 (humans use reasoning to reinforce group identity), this is not to dismiss the first two explanations of Christian skepticism towards science as completely meaningless. Cognitive biases can make it especially difficult to understand some scientific theories, but there is too much cultural and historical variation to religious science skepticism to blame misleading intuitions. These cognitive mechanisms work within larger cultural and social contexts, without which one cannot explain science skepticism. At other times, especially when emotions are engaged, reasoning is short-circuited and core beliefs are defended at all costs. There are, of course, partisans who so identify with their beliefs that there is almost no prospect of changing their minds, but these partisans do not represent most public consumers of information.

In general, however, Christians want reliable information and are willing to spend some of their limited cognitive resources to obtain it. The central complaint

\footnotetext{
${ }^{50}$ Matthew Fisher, Mariel K. Goddu, and Frank C. Keil (2015, 674-87); Adrian F. Ward et al. (2017, 140-54).
} 
of many religious communities is not that experts have knowledge that is incompatible with religious views but rather that the experts are not really experts a view which leads them, in good faith, to spread misinformation. To combat science skepticism in religious communities, more attention should be given to the information landscape in which people operate. How can we help people more clearly differentiate between high- and low-quality information in a digital era that is rife with conflicting information? A key answer will involve the development of institutions of knowledge that can help mediate quality information to the public. Given the limits of individual reason to seek the truth, we solve the problem of distinguishing good from bad information by forming institutions-such as the legal system or university - and collectively practicing intellectual vigilance through a structured contest between different points of views. ${ }^{51}$ Rationality emerges from critical interaction with diverse perspectives, relying on others to help gather and evaluate evidence. It is the social nature of reasoning, formalized in institutions, that is key to the success of the scientific enterprise.

A healthy Christianity in the twenty-first century requires robust institutions that promote evidence-based skepticism and real dissent, that do not reinforce lay commonsense biases or presume that infallible answers are given only to a few select leaders at the top of the hierarchy. Only by building robust institutions can we take a stand against the spread of misinformation in our communities. If the church cannot bring itself to trust the best knowledge produced by the modern world, why would the modern world trust the church in return? ${ }^{52}$

\section{Bibliography}

Barberá, Pablo, John T. Jost, Jonathan Nagler, Joshua A. Tucker, and Richard Bonneau. 2015. "Tweeting From Left to Right: Is Online Political Communication More Than an Echo Chamber?" Psychological Science 26 (10): 1531-42. https://doi.org/10.1177/0956797615594620.

Bishop, Beth A., and Charles W. Anderson. 1990. "Student Conceptions of Natural Selection and Its Role in Evolution." Journal of Research in Science Teaching 27 (5): 415-27. https://doi.org/10.1002/tea.3660270503.

${ }^{51}$ Sperber et al., $(2010,383)$. These social mechanisms are to a considerable extent "articulations of psychological mechanisms linked through extended chains of communication and...institutional patterning" ultimately resulting in a complex and formidable "distributed epistemic assessment system."

${ }^{52}$ An earlier version of the article was published in Josh A. Reeves, Redeeming Expertise: Scientific Trust and the Future of the Church (Baylor University Press, 2021). 
Bolsen, Toby, James N. Druckman, and Fay Lomax Cook. 2015. "Citizens', Scientists', and Policy Advisors' Beliefs about Global Warming:" The ANNALS of the American Academy of Political and Social Science, February. https://doi.org/10.1177/0002716214558393.

Christiano, Thomas. 2017. Review of Review of Against Democracy, by Jason Brennan, May. https://ndpr.nd.edu/news/against-democracy/.

Collins, H. M., and Robert Evans. 2002. "The Third Wave of Science Studies: Studies of Expertise and Experience." Social Studies of Science 32 (2): 235-96.

Collins, H. M., and Robert Evans. 2007. Rethinking Expertise. Chicago: University of Chicago Press.

Cook, John, Ullrich Ecker, and Stephan Lewandowsky. 2015. "Misinformation and How to Correct It." In Emerging Trends in the Social and Behavioral Sciences, 1-17. American Cancer Society.

Drummond, Caitlin, and Baruch Fischhoff. 2017. "Individuals with Greater Science Literacy and Education Have More Polarized Beliefs on Controversial Science Topics." Proceedings of the National Academy of Sciences 114 (36): 9587-92. https://doi.org/10.1073/pnas.1704882114.

Duarte, José L., Jarret T. Crawford, Charlotta Stern, Jonathan Haidt, Lee Jussim, and Philip E. Tetlock. 2015. "Political Diversity Will Improve Social Psychological Science." The Behavioral and Brain Sciences 38: e130.

Dvir-Gvirsman, Shira, Yariv Tsfati, and Ericka Menchen-Trevino. 2016. “The Extent and Nature of Ideological Selective Exposure Online: Combining Survey Responses with Actual Web Log Data from the 2013 Israeli Elections." New Media \& Society 18 (5): 857-77. https://doi.org/10.1177/1461444814549041.

Ecklund, Elaine Howard, Christopher P. Scheitle, Jared Peifer, and Daniel Bolger. 2017. "Examining Links Between Religion, Evolution Views, and Climate Change Skepticism." Environment and Behavior 49 (9): 985-1006. https://doi.org/10.1177/0013916516674246.

Ehret, Phillip J., Aaron C. Sparks, and David K. Sherman. 2017. "Support for Environmental Protection: An Integration of Ideological-Consistency and Information-Deficit Models." Environmental Politics 26 (2): 253-77. https://doi.org/10.1080/09644016.2016.1256960.

Evans, Jonathan St. B. T., and Keith E. Stanovich. 2013. "Dual-Process Theories of Higher Cognition: Advancing the Debate." Perspectives on Psychological Science 8 (3): 223-41.

Fernbach, Philip, and Steven Sloman. 2018. "Opinion I Why We Believe Obvious Untruths." The New York Times, January 20, 2018, sec. Opinion. 
https://www.nytimes.com/2017/03/03/opinion/sunday/why-we-believe-obviousuntruths.html.

Fisher, Matthew, Mariel K. Goddu, and Frank C. Keil. 2015. "Searching for Explanations: How the Internet Inflates Estimates of Internal Knowledge." Journal of Experimental Psychology: General $144 \quad$ (3): 674-87. https://doi.org/10.1037/xge0000070.

Funk, Cary, Courtney Johnson, and Meg Hefferon. 2019. “5 Key Findings about Public Trust in Scientists in the U.S." Pew Research Center. August 5, 2019. https://www.pewresearch.org/fact-tank/2019/08/05/5-key-findings-about-publictrust-in-scientists-in-the-u-s/.

Gentzkow, Matthew, and Jesse M. Shapiro. 2011. "Ideological Segregation Online and Offline." The Quarterly Journal of Economics 126 (4): 1799-1839. https://doi.org/10.1093/qje/qjir044.

Gervais, Will M. 2015. "Override the Controversy: Analytic Thinking Predicts Endorsement of Evolution." Cognition 142 (September): 312-21. https://doi.org/10.1016/j.cognition.2015.05.011.

Gigerenzer, Gerd. 2018. "The Bias Bias in Behavioral Economics." Review of Behavioral Economics 5 (3-4): 303-36. https://doi.org/10.1561/105.00000092.

Gilbert, Daniel T., Michael J. Gill, and Timothy D. Wilson. 2002. “The Future Is Now: Temporal Correction in Affective Forecasting." Organizational Behavior and Human Decision Processes 88 (1): 430-44.

Goldberg, Matthew H., Abel Gustafson, Matthew T. Ballew, Seth A. Rosenthal, and Anthony Leiserowitz. 2019. "A Social Identity Approach to Engaging Christians in the Issue of Climate Change:" Science Communication, July. https://doi.org/10.1177/1075547019860847.

Gustafson, Abel, Seth A. Rosenthal, Matthew T. Ballew, Matthew H. Goldberg, Parrish Bergquist, John E. Kotcher, Edward W. Maibach, and Anthony Leiserowitz. 2019. "The Development of Partisan Polarization over the Green New Deal." Nature Climate Change 9 (12): 940-44. https://doi.org/10.1038/s41558019-0621-7.

Haidt, Jonathan. 2013. The Righteous Mind: Why Good People Are Divided by Politics and Religion. Reprint edition. New York: Vintage.

Hamilton, Lawrence, Matthew Cutler, and Andrew Schaefer. 2012. "Public Knowledge and Concern about Polar-Region Warming." Polar Geography, January. https://doi.org/10.1080/1088937X.2012.684155.

Herritt, Robert. 2016. "Hard to Believe." The New Atlantis, no. 48 (Winter): 79-89. 
Holt, Emily A., T. Heath Ogden, and Susan L. Durham. 2018. “The Positive Effect of Role Models in Evolution Instruction." Evolution: Education and Outreach 11 (1): 11. https://doi.org/10.1186/s12052-018-0086-6.

Irzik, Gürol, and Faik Kurtulmus. 2019. "What Is Epistemic Public Trust in Science?" The British Journal for the Philosophy of Science 70 (4): 1145-66. https://doi.org/10.1093/bjps/axy007.

Johnson, Dominic, and Simon Levin. 2009. "The Tragedy of Cognition: Psychological Biases and Environmental Inaction." Current Science 97 (11): 15931603.

Jones, Robert P., Daniel Cox, and Juhem Navarro-Rivera. 2014. "Believers, Sympathizers, \& Skeptics Why Americans Are Conflicted about Climate Change, Environmental Policy, and Science: Findings from the PRRI/AAR Religion, Values, and Climate Change Survey." Public Religion Research Institute. https://www.prri.org/wp-content/uploads/2014/11/2014-Climate-ChangeFINAL1-1.pdf.

Kahan, Dan M. 2012. “Ideology, Motivated Reasoning, and Cognitive Reflection: An Experimental Study." SSRN Scholarly Paper ID 2182588. Rochester, NY: Social Science Research Network. https://doi.org/10.2139/ssrn.2182588.

Kahan, Dan M. 2016. “On the Sources of Ordinary Science Knowledge and Extraordinary Science Ignorance." SSRN Scholarly Paper ID 2794799. Rochester, NY: Social Science Research Network. https://papers.ssrn.com/abstract=2794799.

Kahan, Dan M. 2017. "Misconceptions, Misinformation, and the Logic of IdentityProtective Cognition." SSRN Scholarly Paper ID 2973067. Rochester, NY: Social Science Research Network. https://doi.org/10.2139/ssrn.2973067.

Kahan, Dan M., Asheley Landrum, Katie Carpenter, Laura Helft, and Kathleen Hall Jamieson. 2017. "Science Curiosity and Political Information Processing." Political Psychology 38 (S1): 179-99. https://doi.org/10.1111/pops.12396.

Kahan, Dan M., Ellen Peters, Erica Cantrell Dawson, and Paul Slovic. 2017. “Motivated Numeracy and Enlightened Self-Government." Behavioural Public Policy 1 (1): 54-86. https://doi.org/10.1017/bpp.2016.2.

Kahan, Dan M., Ellen Peters, Maggie Wittlin, Paul Slovic, Lisa Larrimore Ouellette, Donald Braman, and Gregory Mandel. 2012. "The Polarizing Impact of Science Literacy and Numeracy on Perceived Climate Change Risks." Nature Climate Change 2 (10): 732-35. https://doi.org/10.1038/nclimate1547.

Kahneman, Daniel. 2011. Thinking, Fast and Slow. 1 edition. Farrar, Straus and Giroux.

Kelemen, Deborah A., Joshua Rottman, and Rebecca Seston. 2013. "Professional Physical Scientists Display Tenacious Teleological Tendencies: Purpose-Based 
Reasoning as a Cognitive Default." Journal of Experimental Psychology. General. https://doi.org/10.1037/a0030399.

Kinder, Donald R. 1998. "Opinion and Action in the Realm of Politics." In The Handbook of Social Psychology, Vols. 1-2, 4th Ed, 778-867. New York, NY, US: McGraw-Hill.

Kruger, J., and D. Dunning. 1999. "Unskilled and Unaware of It: How Difficulties in Recognizing One's Own Incompetence Lead to Inflated Self-Assessments." Journal of Personality and Social Psychology 77 (6): 1121-34.

Kumandaş, Bahar, Armagan Ateskan, and Jennie Lane. 2019. "Misconceptions in Biology: A Meta-Synthesis Study of Research, 2000-2014." Journal of Biological Education 53 (4): 350-64. https://doi.org/10.1080/00219266.2018.1490798.

Linden, Sander van der, Edward Maibach, and Anthony Leiserowitz. 2019. "Exposure to Scientific Consensus Does Not Cause Psychological Reactance." $\begin{array}{lllll}\text { Environmental Communication } & 0 & (0): & 1-8 .\end{array}$ https://doi.org/10.1080/17524032.2019.1617763.

Mannes, Albert E., Richard P. Larrick, and Jack B. Soll. 2012. “The Social Psychology of the Wisdom of Crowds." In Social Judgment and Decision Making, 227-42. Frontiers of Social Psychology. New York, NY, US: Psychology Press.

McCoy, Charles. 2017. "Anti-Vaccination Beliefs Don't Follow the Usual Political Polarization." The Conversation. August 23, 2017. http://theconversation.com/anti-vaccination-beliefs-dont-follow-the-usualpolitical-polarization-81001.

Mercier, Hugo, and Dan Sperber. 2011. "Why Do Humans Reason? Arguments for an Argumentative Theory." The Behavioral and Brain Sciences 34 (2): 57-74; discussion 74-111. https://doi.org/10.1017/S0140525X10000968.

Miller, Jon, Eugenie Scott, and Shinji Okamoto. 2006. "Public Acceptance of Evolution." Science (New York, N.Y.) 313 (September): 765-66. https://doi.org/10.1126/science.1126746.

Morris, Henry M., and Henry M. Morris III. 1974. Many Infallible Proofs: Evidences for the Christian Faith. New Leaf Publishing Group.

Nickerson, Raymond. 1998. "Confirmation Bias: A Ubiquitous Phenomenon in Many Guises." 1998. https://journals.sagepub.com/doi/10.1037/1089-2680.2.2.175.

Nyhan, Brendan, and Jason Reifler. 2010. "When Corrections Fail: The Persistence of Political Misperceptions." Political Behavior 32 (2): 303-30.

Nyhan, Brendan, Jason Reifler, Sean Richey, and Gary L. Freed. 2014. "Effective Messages in Vaccine Promotion: A Randomized Trial." Pediatrics, March, peds.2013-2365. 
Pennycook, Gordon, Jonathan A. Fugelsang, and Derek J. Koehler. 2015. “Everyday Consequences of Analytic Thinking." Current Directions in Psychological Science 24 (6): 425-32. https://doi.org/10.1177/0963721415604610.

Pennycook, Gordon, and David G. Rand. 2019. “Lazy, Not Biased: Susceptibility to Partisan Fake News Is Better Explained by Lack of Reasoning than by Motivated Reasoning." Cognition, The Cognitive Science of Political Thought, 188 (July): 3950. https://doi.org/10.1016/j.cognition.2018.06.011.

Pentland, Alex. 2016. "To Rescue Democracy, Go Outside." Nautilus. October 13, 2016. http://nautil.us/issue/41/selection/to-rescue-democracy-go-outside.

Plato. 1987. Gorgias. Translated by Donald J. Zeyl. Hackett Publishing.

Porter, Ethan, and Thomas J. Wood. 2019. False Alarm: The Truth about Political Mistruths in the Trump Era. Cambridge: Cambridge University Press.

Porter, Ethan, and Thomas J. Wood. 2020. "No, We're Not Living in a Post-Fact World." POLITICO Magazine. January 4, 2020. https://www.politico.com/news/magazine/2020/01/04/some-good-news-for2020-facts-still-matter-092771.

Pronin, Emily, Daniel Y. Lin, and Lee Ross. 2002. "The Bias Blind Spot: Perceptions of Bias in Self versus Others." Personality and Social Psychology Bulletin 28 (3): 369 81. https://doi.org/10.1177/0146167202286008.

Reeves, Josh A. 2021. Redeeming Expertise: Scientific Trust and the Future of the Church. Baylor University Press.

"Religious Identities and the Race Against the Virus: Successes and Opportunities for Engaging Faith Communities on COVID-19 Vaccination." 2021. PRRI and IFYC. https://www.prri.org/research/religious-vaccines-covid-vaccination/.

Roozenbeek, Jon, and Sander van der Linden. 2019. "Fake News Game Confers Psychological Resistance against Online Misinformation." Palgrave Communications 5 (1): 1-10. https://doi.org/10.1057/s41599-019-0279-9.

Rutjens, Bastiaan T., Sander van der Linden, and Romy van der Lee. 2021. "Science Skepticism in Times of COVID-19." Group Processes E Intergroup Relations 24 (2): 276-83. https://doi.org/10.1177/1368430220981415.

Sarathchandra, Dilshani, Mark C. Navin, Mark A. Largent, and Aaron M. McCright. 2018. "A Survey Instrument for Measuring Vaccine Acceptance." Preventive Medicine 109: 1-7. https://doi.org/10.1016/j.ypmed.2018.01.006.

Scharrer, Lisa, Yvonne Rupieper, Marc Stadtler, and Rainer Bromme. 2017. “When Science Becomes Too Easy: Science Popularization Inclines Laypeople to Underrate Their Dependence on Experts." Public Understanding of Science 26 (8): 1003-18. https://doi.org/10.1177/0963662516680311.

“Science Scorned." 2010. Nature 467 (7312): 133-133. https://doi.org/10.1038/467133a. 
Shtulman, Andrew, and Kate McCallum. 2014. "Cognitive Reflection Predicts Science Understanding." Proceedings of the Annual Meeting of the Cognitive Science Society 36 (36). https://escholarship.org/uc/item/4t79p8pj.

Sperber, Dan, Fabrice Clément, Christophe Heintz, Olivier Mascaro, Hugo Mercier, Gloria Origgi, and Deirdre Wilson. 2010. “Epistemic Vigilance." Mind \& Language 25 (4): 359-93.

Stanovich, Keith. Rationality and the Reflective Mind. Oxford: Oxford University Press, 2011.

Stanovich, Keith E., Richard F. West, and Maggie E. Toplak. 2013. "Myside Bias, Rational Thinking, and Intelligence:" Current Directions in Psychological Science, August. https://doi.org/10.1177/0963721413480174.

Stewart, Katherine. 2020. "The Religious Right's Hostility to Science Is Crippling Our Coronavirus Response." The New York Times, March 27, 2020, sec. Opinion. https://www.nytimes.com/2020/03/27/opinion/coronavirus-trumpevangelicals.html.

Swami, Viren, Martin Voracek, Stefan Stieger, Ulrich S. Tran, and Adrian Furnham. "Analytic Thinking Reduces Belief in Conspiracy Theories." Cognition 133, no. 3 (December 2014): 572-85. https://doi.org/10.1016/j.cognition.2014.08.006.

Thaler, Richard H., and H. M. Shefrin. 1981. "An Economic Theory of Self-Control." Journal of Political Economy 89 (2): 392-406. https://doi.org/10.1086/260971.

Tversky, Amos, and Daniel Kahneman. 1974. "Judgment under Uncertainty: Heuristics and Biases." Science 185 (4157): 1124-31. https://doi.org/10.1126/science.185.4157.1124.

Ward, Adrian F., Kristen Duke, Ayelet Gneezy, and Maarten W. Bos. 2017. “Brain Drain: The Mere Presence of One's Own Smartphone Reduces Available Cognitive Capacity." Journal of the Association for Consumer Research 2 (2): 140-54. https://doi.org/10.1086/691462.

Wood, Thomas, and Ethan Porter. 2019. "The Elusive Backfire Effect: Mass Attitudes' Steadfast Factual Adherence." Political Behavior 41 (1): 135-63. https://doi.org/10.1007/s11109-018-9443-y. 